\title{
Lung function prediction equations derived from healthy South African gold miners
}

\author{
Eva Hnizdo, Gavin Churchyard, Rob Dowdeswel
}

\begin{abstract}
Objectives-To estimate lung function prediction equations and to identify appropriate normal reference values for the population of about 250000 of South African gold miners.

Methods-Data from a lung function screening programme conducted at a large South African gold mine from 1994 to 1998 were used to estimate the lung function prediction equations. The most reliable period of lung function testing was identified in a previous study of a temporal pattern in reliability, and lung function tests from this period were used. Miners with a history of pulmonary tuberculosis or with radiological abnormalities were excluded from the study. The prediction equations were estimated cross sectionally on 15772 black and 2752 white miners, and published reference equations that fitted most closely the observed data were identified.
\end{abstract}

Results-The estimated prediction equations for forced vital capacity (FVC) are as follows: for black men, FVC (1)=2.901-0.025 $\times$ age $+4.655 \times$ height; and for white men, $\mathrm{FVC}(1)=-4.407-0.036 \times$ age + $5.940 \times$ height. For forced expiratory volume in one second $\left(F E V_{1}\right)$ these equations are: for black men, $\mathrm{FEV}_{1}(1)=-1.654-$ $0.30 \times$ age $+3.665 \times$ height; and for white men, $\mathrm{FEV}_{1}(1)=-2.341-0.038 \times$ age $+4.314 \times$ height. Units are years for age and metres for height. Knudson's and the European Community of Coal and Steel (ECCS) reference values provided the closest fit to the data on lung function of white miners, but the lower limits of normal from the ECCS equations were the closest to the observed one sided lower $95 \%$ confidence intervals (95\% CIs). For black miners, reference equations that fitted best were derived by Louw et al on asymptomatic black South African men unexposed to occupational dust. There were significant differences between the two groups of miners in the estimated height adjusted mean lung function values for a 40 year old $1.7 \mathrm{~m}$ tall man $(220 \mathrm{ml}(5.2 \%)$ for FVC and $110 \mathrm{ml}(3.2 \%)$ for $\mathrm{FEV}_{1}$ ); white men had higher FVC and $\mathrm{FEV}_{1}$, but lower $\mathrm{FEV}_{1} / \mathrm{FVC}$ ratio. The ECCS reference values scaled by a conversion factor of 0.93 for the FVC and 0.95 for the $\mathrm{FEV}_{1}$ provided close fits to the data for black miners, but the rate of decline with age was higher than that in the observed data. None of the linear equations provided a good fit for the 20-29 and more than 55 years old age categories.
Conclusion-The ECCS and Knudson equations provided the best fit to the data for white miners, whereas the equations by Louw et al estimated on asymptomatic black South African bank workers provided the best fit to the data for black miners. The ECCS reference values scaled by a factor of 0.93 for FVC and by 0.95 for $\mathrm{FEV}_{1}$ provided close fits, but the rate of decline with age was higher than that in the data for black miners.

(Occup Environ Med 2000;57:698-705)

Keywords: silica dust; miners; pulmonary function reference equations

The availability of appropriate normal reference values is fundamental to a workplace lung function monitoring programme. Good reference values allow for an early detection of accelerated loss of pulmonary function, for assessment of fitness to work in certain job categories, to wear respirators, and for the diagnosis of a compensational disease, among other purposes. ${ }^{1}$

The South African gold mining industry currently employs about 250000 miners. Because of exposure to dust with a high concentration of crystalline silica, the miners are at risk of developing respiratory diseasessuch as silicosis, chronic obstructive lung disease, and pulmonary tuberculosis. Also, there is an extensive population of ex-miners who may be eligible for compensation due to existing lung diseases. Legislation for screening of pulmonary function in all miners has been introduced in South Africa only recently. ${ }^{1}$ However, there is uncertainty as to the most appropriate reference values for assessing the miners. The European Community for Coal and Steel (ECCS) reference values ${ }^{2}$ have been suggested for general use, ${ }^{3}$ but their suitability, particularly for black miners, has never been evaluated. The goal of this study was to identify reference equations appropriate for the large population of gold miners who are predominantly black, but with a significant white subpopulation. The approach adopted was to estimate prediction curves for lung function measurement obtained on a healthy subset of current black and white gold miners and to evaluate how well published reference equations $^{45}$ compare with the estimated prediction curves.

Material and methods

STUDY POPULATION

Miners from a large South African gold mining company who had spirometry performed routinely at entry into the industry (initial 


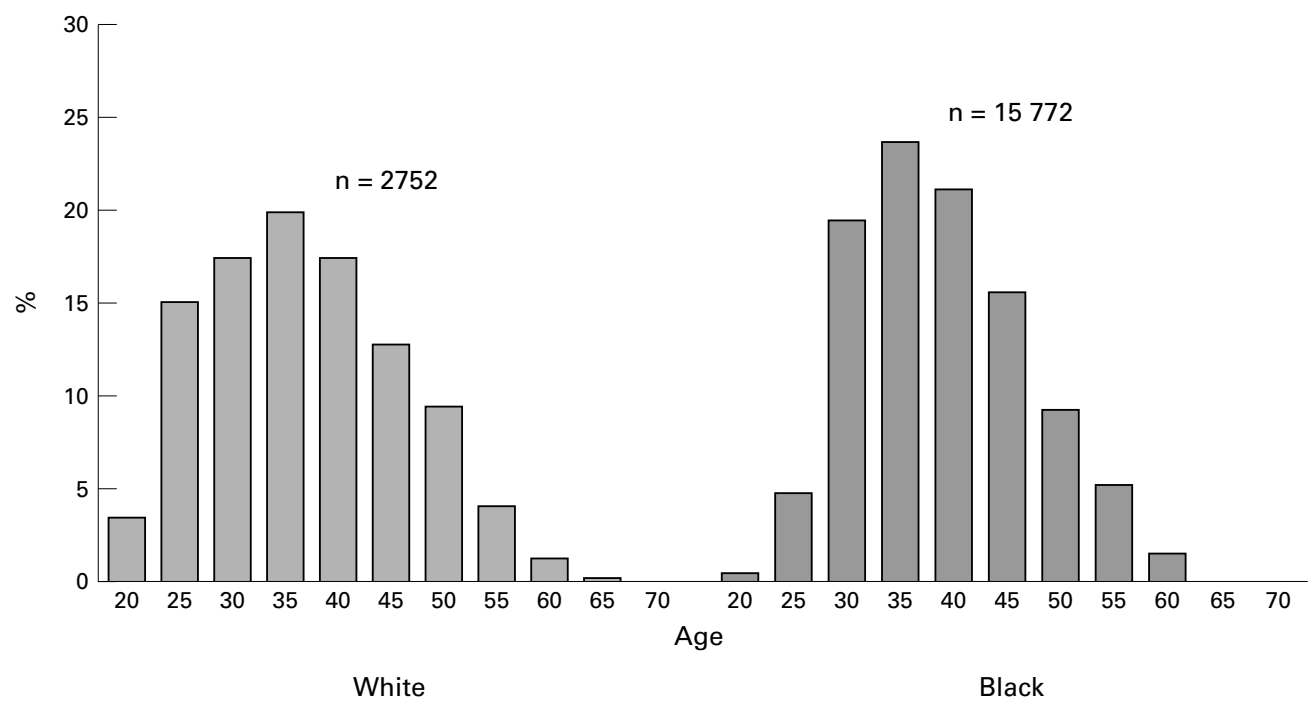

Figure 1 Age distribution for white and black miners.

examination), periodically at 3 year intervals (periodic examination), and on leaving the company (exit examination) comprised the study population. The lung function monitoring programme started in May 1994 and served a population of 71515 miners in 1994 , which decreased to 43359 miners by 1998 .

SPIROMETRY MEASUREMENTS

Maximal forced expiratory manoeuvres were recorded with a Hans Rudolph pneumotachograph (Flowscan, Electromedical Systems). The system software required and validated calibration with a 3 litre syringe and allowed keyboard entry of barometric pressure and ambient temperature for the correction to body temperature, pressure, and saturation (BTPS) conditions. Calibration was done 3-4 times a day. During testing, flow versus volume tracings were displayed. A minimum of three acceptable and reproducible forced expiratory manoeuvres are obtained according to the standards recommended by the American Thoracic Society (ATS). ${ }^{7}$ All testing was done by nursing personnel with a college diploma specialisation in spirometry testing and trained in the techniques of performing spirometry to ATS standards. Height was measured to the nearest centimetre (without shoes). Data recorded for each test included the date of test, date of birth, height, weight, forced vital capacity (FVC), forced expiratory volume in one second $\left(\mathrm{FEV}_{1}\right)$, and forced expiratory flow at $25 \%-75 \%$ of forced vital capacity $\left(\mathrm{FEF}_{25-75 \%}\right)$.
RELIABILITY OF THE LUNG FUNCTION DATA

During the period May 1994 to March 1998, 113120 spirograms were recorded in a computerised database. In a previous study ${ }^{6}$ we have examined reliability of the spirograms over time, and in the present study we used data from the most reliable period from January 1995 to August 1996 for which the average coefficient of reliability, G, was 0.93 (the size of random error of measurement was $7 \%)$. In total, 45053 tests were done during the reliable period. ${ }^{6}$ Of these, 36777 (31 108 on black, and 3270 on white miners) were on miners for whom a complete history of pulmonary tuberculosis and chest radiology was available. The remaining tests were from contract workers with incomplete information. From the 31108 tests on black miners, we excluded 3905 subjects with a history of pulmonary tuberculosis and 1485 subjects with radiological changes (pulmonary tuberculosis, pneumoconiosis, pneumonia, cardiomegaly, pleural changes, etc; there was an overlap between cases). (All cases of pulmonary tuberculosis were computerised from 1979 to 1998 . The yearly radiological screening was done on minature $100 \times 100 \mathrm{~mm}$ chest radiographs, and subjects with abnormalities were recorded cross sectionally from 1994 to 1998.) Of the remaining 26024 tests, we excluded 71 miners whose age was less than 20 years or more than 63 years, and 255 miners $(0.98 \%)$ and 84 subjects whose lung function or height measurements were outside the $99.98 \%$ confidence

Table 1 The observed means for lung function, the prediction curves, and predicted values for black and white miners

\begin{tabular}{|c|c|c|c|c|c|c|c|c|}
\hline \multirow[b]{2}{*}{ Lung function } & \multicolumn{2}{|c|}{ Observed values } & \multicolumn{3}{|c|}{ Regression coefficient (SE) } & \multirow[b]{2}{*}{$R^{2}(\%)$} & \multirow[b]{2}{*}{$S E E$} & \multirow{2}{*}{$\begin{array}{l}\text { Prediction, } \\
\text { age } 40, \\
\text { height } 1.7 \mathrm{~m}\end{array}$} \\
\hline & Mean & $S E$ & Intercept & Age & Height & & & \\
\hline \multicolumn{9}{|c|}{ Black miners $\mathrm{n}=15772$, age 38.7 (SE 0.06), height $1.71 \mathrm{~m}$ (SE 0.005): } \\
\hline FVC (1) & 4.10 & 0.005 & $-2.901(0.120)$ & $-0.025(0.001)$ & $4.655(0.068)$ & 33.5 & 0.528 & 4.02 \\
\hline $\mathrm{FEV}_{1}(\mathrm{l})$ & 3.44 & 0.005 & $-1.654(0.109)$ & $-0.030(0.001)$ & $3.665(0.061)$ & 35.5 & 0.477 & 3.38 \\
\hline $\operatorname{FEF}(1 / \mathrm{s})$ & 3.96 & 0.010 & $1.363(0.274)$ & $-0.056(0.001)$ & $2.780(0.154)$ & 14.6 & 1.200 & 3.86 \\
\hline $\mathrm{FEV}_{1} \%$ & 84.1 & 0.055 & $102.56(1.511)$ & $-0.237(0.007)$ & $-5.437(0.848)$ & 7.24 & 6.627 & 83.8 \\
\hline \multicolumn{9}{|c|}{ White miners $n=2752$, age 36.9 (SE 0.06 ), height $1.80 \mathrm{~m}$ (SE 0.001): } \\
\hline FVC (1) & 4.96 & 0.016 & $-4.407(0.339)$ & $-0.036(0.001)$ & $5.940(0.182)$ & 44.1 & 0.547 & 4.24 \\
\hline $\mathrm{FEV}_{1}(1)$ & 4.04 & 0.014 & $-2.341(0.300)$ & $-0.038(0.001)$ & $4.314(0.161)$ & 43.4 & 0.484 & 3.49 \\
\hline $\operatorname{FEF}(1 / \mathrm{s})$ & 4.14 & 0.024 & $0.824(0.640)$ & $-0.050(0.002)$ & $2.866(0.344)$ & 16.8 & 1.039 & 3.70 \\
\hline $\mathrm{FEV}_{1} \%$ & 81.7 & 0.129 & $107.68 \quad(3.601)$ & $-0.172(0.014)$ & $-10.932(1.94)$ & 5.8 & 6.555 & 82.2 \\
\hline
\end{tabular}



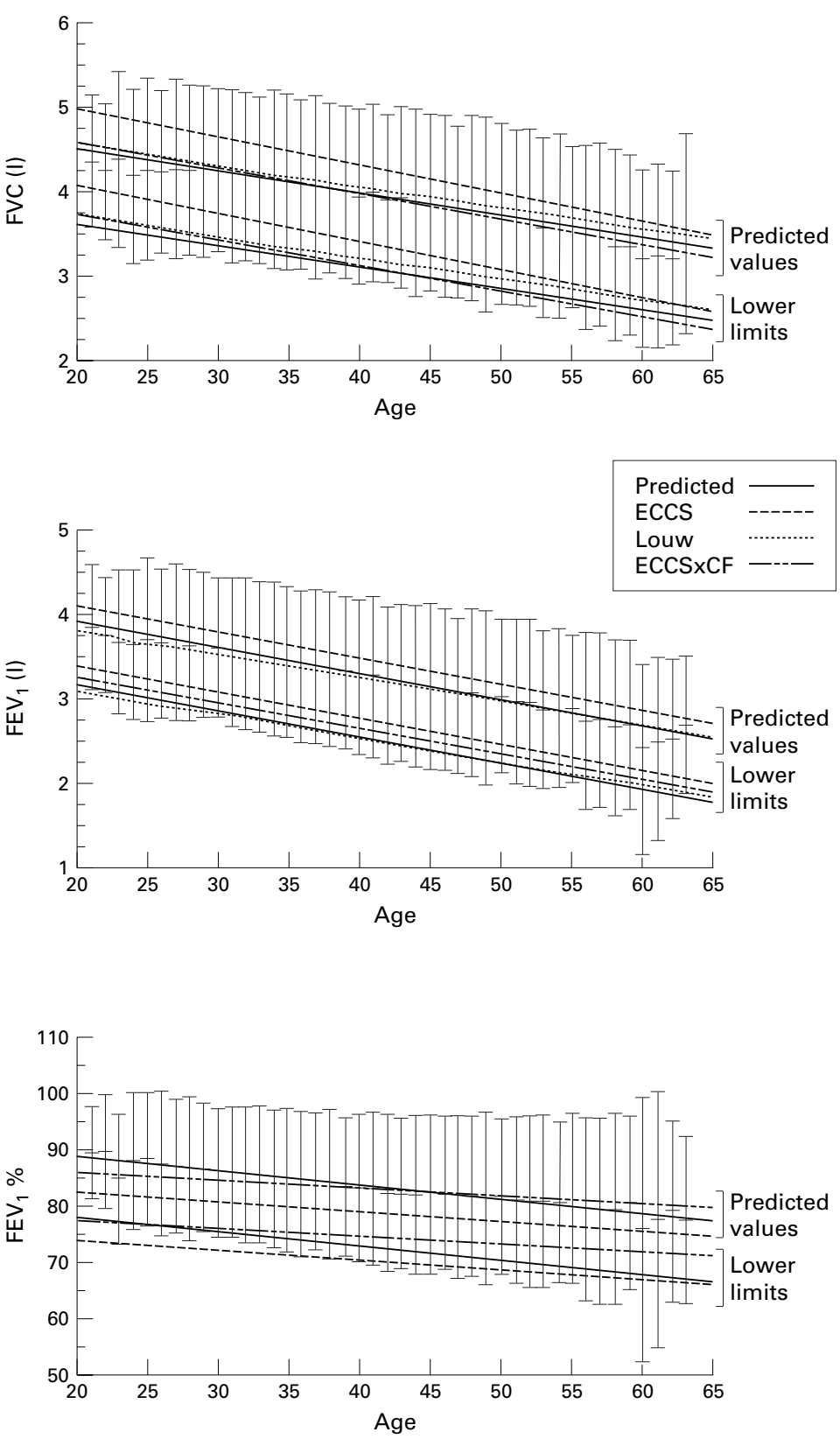

Figure 2 Height standardised mean lung function and 95\% CI plotted against age, for black miners. Overlaid are predicted and reference curves and their respective lower limits of normal, as well as the ECCS curves scaled by a conversion factor of 0.93 for FVC and 0.95 for $F E V_{1}$. used these exclusively as they would provide the most representative sample of current miners. Measurements from both the initial and exit examinations may be potentially lower because of a learning effect and a selection process, respectively. Finally, the prediction equations were estimated on periodic lung function tests from 15772 black and 2752 white miners. Because periodic tests are done at 3 yearly intervals, each miner had one test only.

STATISTICAL ANALYSIS

The prediction equations were estimated separately for black and white miners from the linear regression model $^{8}$

$\mathrm{Y}=\mathrm{b}_{0}+\mathrm{b}_{1} \times$ age $+\mathrm{b}_{2} \times$ height $+\mathrm{b}_{3} \times$ weight $+\mathrm{b}_{4} \times$ age $\times$ height $+b_{5} \times$ age $^{2}$

where $\mathrm{Y}$ is the predicted lung function value for a miner of a given age and height, and $b_{i}$, $i=0,1, \ldots, 5$ are the regression coefficients. Only the variables that contributed significantly to the $R^{2}$ statistic were retained in the final model. The equations of the final model as well as the published reference equations ${ }^{45}$ were then used to predict lung function values of $1.7 \mathrm{~m}$ tall men of different ages. The resulting curves were compared with the mean observed lung function values standardised to the average height of black miners of $1.7 \mathrm{~m}$. To allow the comparison, the lung function measurements were standardised to the height of $1.7 \mathrm{~m}$ as lung function measurement $\times 1.7^{2} / \mathrm{ht}^{2}$. The standardisation for height allowed for comparison of lung function measurements from populations with different mean height (fig 5). Selection of the best fitting reference equations was done by a visual inspection with this method. As most of the published curves did not fit well, a visual inspection was sufficient to identify the best fitting curves.

In the next step, we compared the percentage of miners that fell below the lower limit of normal (LL) for the different reference equations. The LL refers to the one sided lower $95 \%$ CI calculated as $\mathrm{LL}=\mathrm{P}_{(\text {age } 1.7)}-1.645 \times \mathrm{SEE}$, where $\mathrm{P}_{\text {(age, 1.7) }}$ is the age and height specific predicted value, and SEE is the standard error of the estimate of the regression line. ${ }^{49}$ For a homogenous population and a normally distributed variable, it is expected that $5 \%$ of the subjects will have lung function values below the predicted LL. For a reference equation to be applicable to a specific healthy population, the percentage below the reference LL should also be around $5 \%$, otherwise too many or too few subjects will be categorised as abnormal.

In the data on miners there were known systematic effects that could have increased the percentage of miners that fell below the LL. These were age below 30 years or above 55 years (see the observed data points in figs 2 and 3) and changes in lung function due to smoking and exposure to dust. These changes usually start to become evident pathologically at around 35-40 years of age-for example, emphysema, pneumoconiosis. Thus, to minimise the systematic effects of age and the adverse effects of environmental exposures, we 

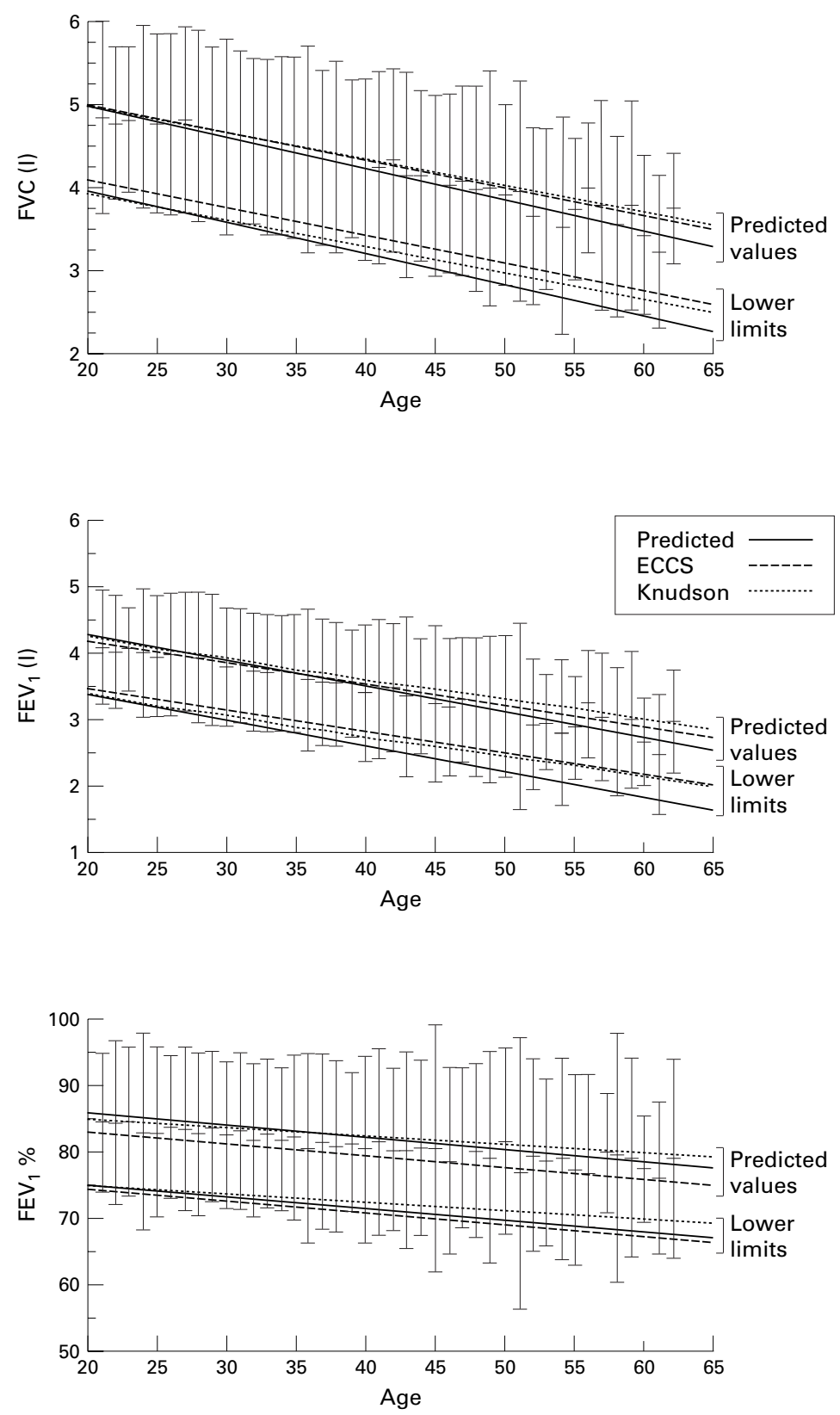

Figure 3 Height standardised mean lung function and 95\% CI plotted against age, for white miners. Overlaid are predicted and reference curves and their respective lower limits of normal. percentile of a distribution of lung function value is the lung function value such that $5 \%$ of subjects have lower values and $95 \%$ of the subjects have higher values. The 5 th percentile is estimated by a non-parametric method from order statistics.

\section{Results}

Figure 1 shows the age distribution of the miners in the study. Table 1 gives the mean lung function and the estimated prediction equations (regression coefficients (SEs)). Because most of the subjects were 30-45 years of age, the contributions of the age $\mathrm{e}^{2}$ and height $\times$ age interaction to the variation explained by the model were small (the additional $R^{2}$ of 0.0002 and 0.0004 , respectively, for $\left.\mathrm{FEV}_{1}\right)$. Thus, the final prediction equations included age and height terms only.

For the black miners, figure 2 shows the observed height standardised lung function means for $\mathrm{FVC}, \mathrm{FEV}_{1}$, and $\mathrm{FEV}_{1} \%$, and the two sided $95 \%$ CI, plotted against age. The predicted curve and the best fitting reference curves, and their respective LLs are shown for each lung function test. The reference curve of Louw at $a \bar{l}$ (measurements done by a vitalograph) provided the best fit to the data, whereas the ECCS curves were too high. The ECCS reference values multiplied by a conversion factor (CF) of 0.93 for FVC and 0.95 for $\mathrm{FEV}_{1}$ were close to the predicted curves. For the white miners, figure 3 shows the observed mean values and the reference equations of the ECCS and Knudson et $a l^{9}$ which provided the best fit to the data.

Figure 2 indicates that the percentage of black miners that falls below the LL of the ECCS curve is large for younger age groups, but decreases for older age groups. However, a somewhat different trend is found for white miners (figure 3), where the observed means start to decline after 40 years of age more rapidly than the ECCS and Knudson's predictions. To determine the percentage of subjects that were below the LLs, we used the cross section of 30-35 year old miners, because for these miners the observed means corresponded closely with the reference curves (figs 2 and 3 ) and this subgroup is least likely to be affected by systematic effects already discussed. The percentages that were below the LLs for the different reference curves for the 30-35 year olds are shown in figure 4 . Figure 4 shows the frequency distribution for the height standardised FVC, $\mathrm{FEV}_{1}$, and $\mathrm{FEV}_{1} \%$. Superimposed over each observed frequency distribution is a normal curve derived from the observed mean (SDs). The normal curves derived from the means predicted by the equations from the ECCS and Louw et al and from their respective SEE values are also shown in figure 4. (The SEE for the curve of Louw et al was available only for models in which the ratio of sitting over standing height was fitted. As the SEE was similar to the models which used standing height only, we used this SEE value.) The percentages below the LLs are shown in table 2 . Table 2 presents, for the 30-35 year olds, the descriptive statistics for the observed lung function and the LLs, and the percentage of 

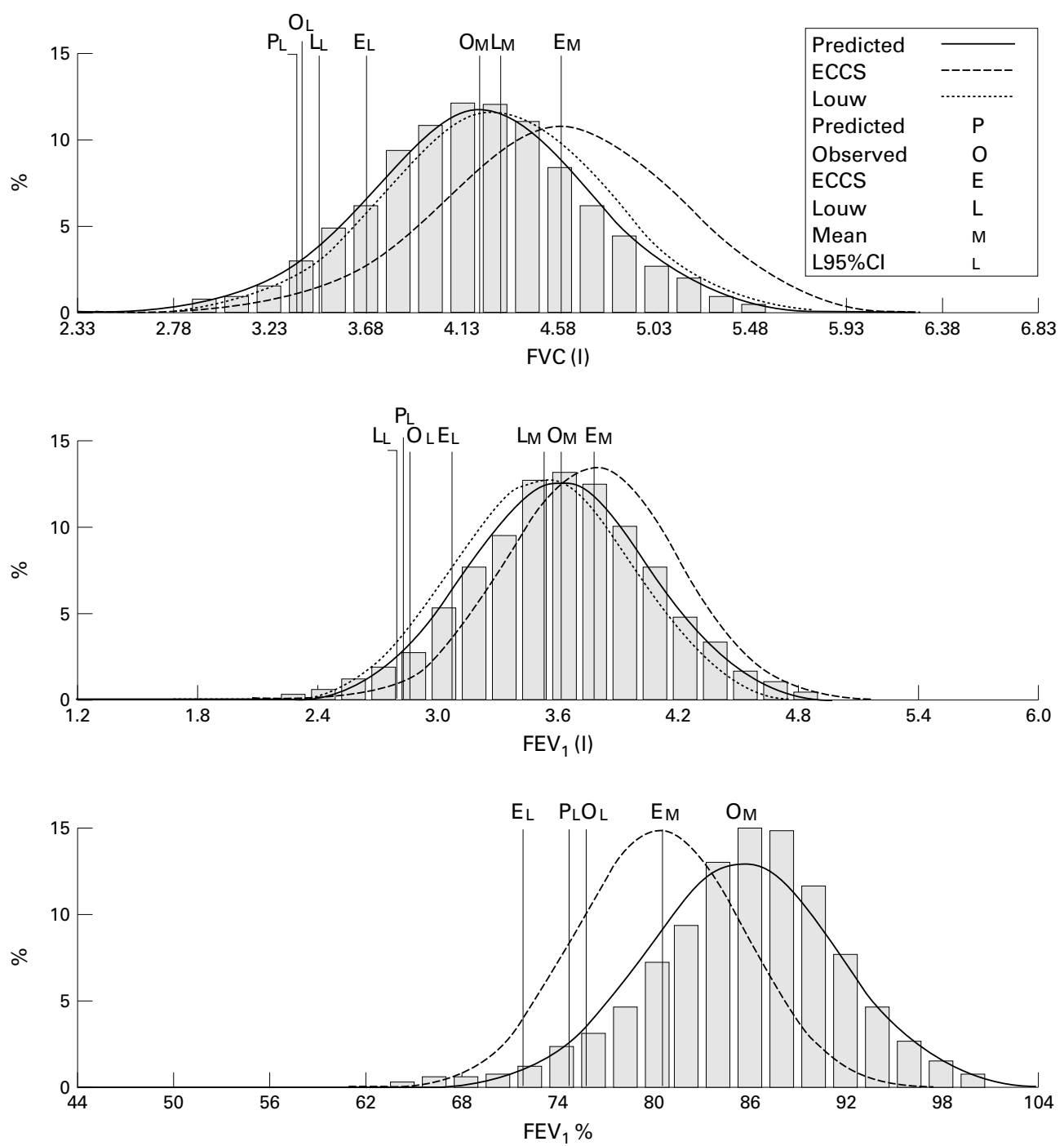

Figure 4 The frequency distribution for height standardised lung function for the cross section of 30-35 year old black miners.

subjects below the LLs, for each equation. Louw et $a \bar{l}$ did not provide a reference equation for the $\mathrm{FEV}_{1} \%$.

The first part of table 3 presents descriptive statistics for the percentage predicted lung function values. The second part of table 3 presents the percentage predicted values that were derived from our prediction equation, the equations of Louw et al, and ECCS equations, and that corresponded with the 5 th percentile and with the one sided lower 95\% CI for 10 year age categories, for black miners only.

\section{Discussion}

The objective of the study was to identify reference equations appropriate for the large population of South African gold miners who are predominantly black, but with a notable white subpopulation. The question also arises whether a common reference equation can be used for all the miners irrespective of race, bearing in mind that the reference curves could serve various purposes - such as assessment of fitness to work in certain job categories, diagnosis of compensable disease

Table 2 Descriptive statistics for height standardised lung function for 30-35 year old workers, and the lower limits of normal, and \% rejected for the predicted and selected reference equations

\begin{tabular}{|c|c|c|c|c|c|c|c|}
\hline Lung function & Mean & $S D$ & Skewness & $\begin{array}{l}\text { Lower } \\
95 \% C I\end{array}$ & \multicolumn{3}{|c|}{$\begin{array}{l}\text { Lower limit of normal; \% rejected for the different } \\
\text { equations }\end{array}$} \\
\hline \multicolumn{5}{|c|}{ Black miners, $\mathrm{n}=4503$, age $=32.6(\mathrm{SD} 1.7)$, height $=1.7$ : } & Predicted & Louw & ECCS \\
\hline FVC (1) & 4.21 & 0.51 & 0.14 & 3.37 & $3.34 ; 4.4 \%$ & $3.44 ; 6.6 \%$ & $3.68 ; 14.9 \%$ \\
\hline $\mathrm{FEV}_{1}(\mathrm{l})$ & 3.60 & 0.46 & -0.03 & 2.84 & $2.81 ; 4.3 \%$ & $2.78 ; 3.8 \%$ & $3.07 ; 12.5 \%$ \\
\hline $\mathrm{FEV}_{1} \%$ & 85.6 & 6.11 & -0.74 & 75.5 & $74.7 ; 3.8 \%$ & NA & $71.7 ; 1.2 \%$ \\
\hline \multicolumn{5}{|c|}{ White miners, $\mathrm{n}=620$, age $=32.7(\mathrm{SD} 1.7)$, height $=1.8$ : } & Predicted & Knudson & ECCS \\
\hline FVC (1) & 4.54 & 0.53 & 0.15 & 3.66 & $3.62 ; 4.09 \%$ & $3.54 ; 3.0 \%$ & $3.68 ; 5.3 \%$ \\
\hline $\mathrm{FEV}_{1}(1)$ & 3.74 & 0.45 & -0.01 & 3.01 & $2.96 ; 4.9 \%$ & $2.98 ; 4.6 \%$ & $3.06 ; 6.6 \%$ \\
\hline $\mathrm{FEV}_{1} \%$ & 82.5 & 5.8 & -0.27 & 73.0 & $72.7 ; 4.6 \%$ & $73.0 ; 5.1 \%$ & $71.7 ; 3.1 \%$ \\
\hline
\end{tabular}


Table 3 The \% predicted corresponding with the 5th percentile and the one sided $95 \%$ CI for different equations, black miners only

\begin{tabular}{|c|c|c|c|c|c|c|c|c|c|c|}
\hline \multirow[b]{2}{*}{ Age } & \multirow[b]{2}{*}{$n$} & \multirow[b]{2}{*}{ Mean } & \multirow[b]{2}{*}{$S D$} & \multirow[b]{2}{*}{ Skewness } & \multicolumn{2}{|c|}{ Predicted equation } & \multicolumn{2}{|c|}{ Louw's equation } & \multicolumn{2}{|c|}{ ECCS equation } \\
\hline & & & & & 5th Percentile & $95 \% C I$ & 5th Percentile & $95 \% C I$ & 5th Percentile & $95 \% C I$ \\
\hline \multicolumn{11}{|l|}{ FVC: } \\
\hline$<30$ & 1692 & 99.2 & 11.8 & 0.07 & 80.6 & 79.7 & 78.7 & 78.0 & 72.6 & 72.0 \\
\hline $30-39$ & 7430 & 100.6 & 12.4 & 0.17 & 80.9 & 80.2 & 78.9 & 78.2 & 73.8 & 73.0 \\
\hline $40-49$ & 4947 & 100.8 & 13.7 & 0.15 & 79.5 & 78.3 & 77.2 & 76.1 & 73.4 & 72.1 \\
\hline$\geqslant 50$ & 1704 & 99.9 & 14.6 & 0.07 & 76.1 & 75.8 & 73.6 & 73.3 & 71.7 & 70.8 \\
\hline \multicolumn{11}{|l|}{$\mathrm{FEV}_{1}:$} \\
\hline$<30$ & 1692 & 99.6 & 12.3 & -0.22 & 80.4 & 79.4 & 82.5 & 81.7 & 76.7 & 75.7 \\
\hline $30-39$ & 7430 & 100.1 & 13.1 & -0.01 & 78.9 & 78.5 & 80.7 & 80.3 & 75.2 & 74.9 \\
\hline $40-49$ & 4947 & 99.9 & 15.0 & -0.17 & 75.3 & 75.2 & 76.3 & 76.3 & 71.8 & 71.7 \\
\hline$\geqslant 50$ & 1704 & 99.9 & 16.8 & 0.23 & 71.3 & 72.4 & 71.2 & 72.7 & 68.0 & 68.9 \\
\hline \multicolumn{11}{|l|}{$\mathrm{FEV}_{1} \%$ : } \\
\hline$<30$ & 1692 & 100.5 & 7.0 & -0.68 & 88.5 & 89.0 & NA & NA & 94.6 & 95.0 \\
\hline $30-39$ & 7430 & 99.9 & 7.3 & -0.74 & 87.3 & 87.9 & NA & NA & 92.6 & 93.3 \\
\hline $40-49$ & 4947 & 99.8 & 8.5 & -0.94 & 84.9 & 85.9 & NA & NA & 89.3 & 90.6 \\
\hline$\geqslant 50$ & 1704 & 100.6 & 9.7 & 0.97 & 82.5 & 84.7 & NA & NA & 86.3 & 88.6 \\
\hline
\end{tabular}

Table 4 Comparison between studies of occupational groups done on black men in South Africa at higher altitude

\begin{tabular}{|c|c|c|c|c|c|}
\hline \multirow[b]{2}{*}{ First author } & \multirow{2}{*}{$\begin{array}{l}\text { Mean age }(y) \\
\text { Mean height }(\mathrm{cm})\end{array}$} & \multirow[b]{2}{*}{ Altitude } & \multicolumn{2}{|c|}{ Men, age $38 y$, height $171 \mathrm{~cm}$} & \multirow[b]{2}{*}{ Type of sample } \\
\hline & & & $F E V_{1}(95 \% C I)$ & $F V C(95 \% C I)$ & \\
\hline White $e t a l^{12}$ & $36.1,167.3$ & 1500 & $4.12(3.99$ to 4.25$)$ & $3.46(3.36$ to 3.56$)$ & Textile workers \\
\hline Louw et $a \bar{l}$ & $41.1,169.7$ & 1700 & $4.21(4.14$ to 4.28$)$ & $3.44(3.57$ to 3.51$)$ & Bank workers, autolink \\
\hline Hessel and Sluis-Cremer ${ }^{14}$ & $41.6,171.4$ & 400 & $4.13(-)$ & $3.29(-)$ & Vermiculite miners \\
\hline Coetzee, cited in ${ }^{12}$ & $33.1,169.4$ & 1700 & $4.30(4.25$ to 4.35$)$ & $3.55(3.50$ to 3.60$)$ & Asbestos workers \\
\hline Mokoetle et $a l^{13}$ & $42.0,168.7$ & 1700 & $4.42(-)$ & $3.47(-)$ & University workers \\
\hline Fox, cited in ${ }^{12}$ & $34.4,171.7$ & 1200 & $4.20(4.16$ to 4.24$)$ & $3.52(3.46$ to 3.58$)$ & Copper or nickel miners \\
\hline Our study & $38.7,170.8$ & 1200 & $4.12(4.12$ to 4.12$)$ & 3.47 (3.47 to 3.47$)$ & Gold miners \\
\hline
\end{tabular}

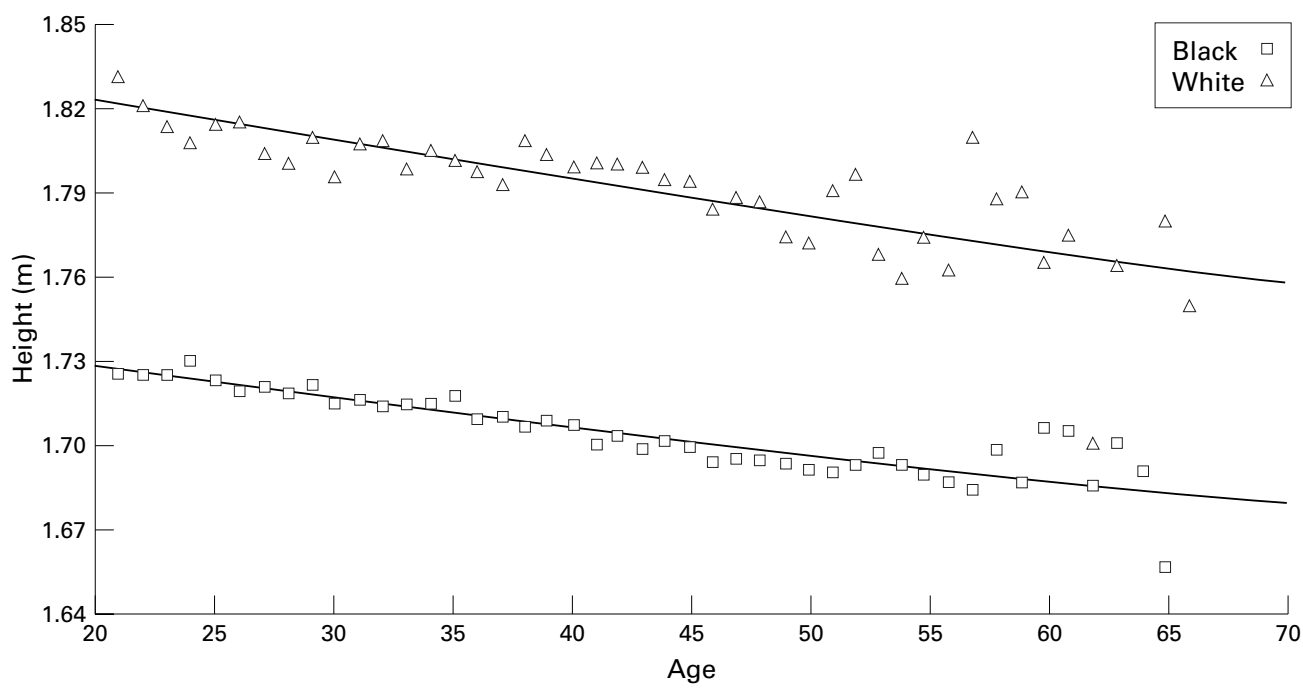

Figure 5 Relation between height and age for black and white miners.

or an early detection of accelerated loss of lung function.

We estimated prediction equations from the data obtained in a lung function screening programme and compared these with published reference values. There were large differences in the observed mean lung function values between white and black miners. These were $860 \mathrm{ml}(17.3 \%)$ for FVC, $630 \mathrm{ml}(14.9 \%)$ for $\mathrm{FEV}_{1},-180 \mathrm{ml}(-6.8 \%)$ for $\mathrm{FEF}_{25-75 \%}$, and $-2.38 \%\left(-2.9 \%\right.$ ) for $\mathrm{FEV}_{1} \%$ (table 1). However, after adjustment for age and height, the differences for a 40 year old $1.7 \mathrm{~m}$ tall man decreased substantially to $220 \mathrm{ml}(5.2 \%)$ for FVC, $110 \mathrm{ml}(3.2 \%)$ for $\mathrm{FEV}_{1},-160 \mathrm{ml}$ $(-4.3 \%)$ for $\mathrm{FEF}_{25-75 \%}$, and $-1.6 \%(-2.0 \%)$ for $\mathrm{FEV}_{1} \%$. The results show that height is responsible for a large percentage of the observed difference, however, the remaining differences after adjustment for age and height were still significant.

Of the reference equations published by ATS, ${ }^{45}$ the ECCS and Knudson equations corresponded most closely with the prediction curves for white miners (fig 3). However, the observed data showed a steeper decline from about 35 years of age. This may be due to the effect of smoking and exposure to dust previously documented in white gold miners. ${ }^{11}$ The observed $\mathrm{FEV}_{1} \%$ values were higher, however, than the ECCS values. The percentage of miners that were below the LLs of the ECCS and Knudson equations were similar and varied around $5 \%$. For the $30-35$ year olds, the percentage of subjects below the LL for the ECCS equation was $5.3 \%$ for FVC and $6.6 \%$ for $\mathrm{FEV}_{1}$, whereas for the Knudson's equation it was $3.0 \%$ and $4.6 \%$, respectively (table 4 ). 
For black miners, the reference equations that fitted best were those derived for black South African men by Louw at $a \bar{l}$ with a vitalograph (fig 2). The ECCS reference equations are commonly used in South Africa for all subjects, either with an ethnic conversion factor of 0.88 for black men (as recommended by ATS $^{4}$ ), or without a conversion factor. The data from the present study show that the ECCS reference values are much higher than the observed lung function values, the difference being almost $500 \mathrm{ml}$ at 20 years of age for FVC (figure 2). The percentages below the LLs for equations of Louw and the ECCS, shown in figure 3 and table 2, are also substantially different. For the Louw equation, the percentage rejected was $6.6 \%$ for $\mathrm{FVC}$ and $3.8 \%$ for $\mathrm{FEV}_{1}$, whereas for the ECCS equation the corresponding values were $14.9 \%$ and $12.5 \%$. The ECCS reference values scaled by a factor of 0.93 for $\mathrm{FVC}$ and 0.95 for $\mathrm{FEV}_{1}$ provided the closest fit to the observed data and the predicted curves (fig 1). The scaling down by $8 \%$ for FVC and $5 \%$ for $\mathrm{FEV}_{1}$, was higher than the differences found for the age and height adjusted lung function means which were $5.2 \%$ for FVC and $3.2 \%$ for $\mathrm{FEV}_{1}$. This reflects the fact that white miners had lower observed values than the ECCS curves because of a steeper decline with age.

The differences in the regression coefficient for age in table 1 show a steeper decline with age in white miners, especially for FVC. The predicted curves for FVC and $\mathrm{FEV}_{1}$, and the LLs were parallel with the reference curves of Louw et al derived from asymptomatic, healthy non-smokers (fig 2), but the white workers had a steeper slope than the ECCS curve. One of the reasons for these differences may be that fewer black miners smoke, and if they do so, then they smoke fewer cigarettes (five cigarettes a day) than white miners (over 20 cigarettes a day). It is interesting to note that for FVC, the curve of Louw et al as well as the predicted curve came closer to the ECCS curve (fig 2) with increasing age. This reflects the steeper slope with age for the ECCS curves. The reason for the steeper slope for the ECCS curve is not clear.

The results also show that black miners have higher $\mathrm{FEV}_{1} \%$, but slightly higher decline in $\mathrm{FEV}_{1} \%$, compared with the ECCS curve (fig 2). For 30-35 year old black miners, the observed mean $\mathrm{FEV}_{1} \%$ was $85.5 \%$, the observed one sided $95 \%$ CI was $75.5 \%$, and the LL derived from all data was $74.7 \%$ (table 2). By comparison, the predicted $\mathrm{FEV}_{1} \%$ mean from the ECCS equation was $80.4 \%$ and the LL derived from the ECCS equation was $71.7 \%$. For $30-35$ year old white miners, the mean observed $\mathrm{FEV}_{1} \%$ was $82.5 \%$ and the observed one sided lower $95 \%$ CI was $73.0 \%$ (table 2).

When compared with other published studies, the prediction equations for black gold miners agree most closely with those found in other studies of South African black men occupationally exposed to dust (table 4$).^{12} 13$ For FVC, the predicted values for a 38 year old and $1.7 \mathrm{~m}$ tall male gold miner were similar to those found for textile workers, ${ }^{12}$ bank workers, ${ }^{5}$ and other industrial workers. ${ }^{12-14}$ This result suggests that the high ratio found in this study may be due to a real effect. However, the data in table 4 also suggest that the groups exposed to dust may have lower $\mathrm{FEV}_{1}$ values than the unexposed subjects, and that reference values estimated on healthy South African black men not exposed to dust should preferably be used for the miners.

By comparison with our study and other studies of black workers, a most recent study of black university workers from Johannesburg, South Africa, ${ }^{13}$ found similar $\mathrm{FEV}_{1}$ values, but the FVC values were systematically higher than those predicted by our and other studies; the estimated increase in FVC was substantial and ranged from $120 \mathrm{ml}$ at 20 years to $200 \mathrm{ml}$ at 60 years of age. The explanation provided for the higher FVC was the changing socioeconomic status of black workers in South Africa. The socioeconomic factors associated with FVC in the study were job category and education. The socioeconomic factors were not associated with $\mathrm{FEV}_{1}$. Smoking was not found to be a risk factor for $\mathrm{FEV}_{1}$ or FVC. The effect of socioeconomic factors is also apparent from a secular trend found in FVC measured in different studies of urban black workers done from the $1970 \mathrm{~s}$ to the $1990 \mathrm{~s}$, which ranged from $3.72-3.98$ to $4.24-4.42$, respectively. ${ }^{13}$ In our study, we found a strong relation between height and age for black and white miners (fig 5), although some of it was due to aging, there was an apparent cohort effect. Changing socioeconomic status, which includes nutrition from birth that results in increased height, stronger build, and lower respiratory morbidity, must play an important part on the respiratory variables of the black South African population ${ }^{15}$ whose socioeconomic status is generally improving with urbanisation and education. To take cognisance of that trend, estimation of reference values should be repeated every decade or so in accordance with the recommendations made by the ATS.

Based on these results and given the current circumstances, it seems that the available options are to use the ECCS equations on all miners, with a scaling factor for the black miners, or to use the ECCS equations on white miners and the equations of Louw et al on black miners. The curves of Louw et al provided an excellent fit to the data, whereas the ECCS curves were too steep with age. From an epidemiological view, the use of the ECCS reference equations without any scaling for all the miners is not recommended. Although the difference of $8 \%$ for FVC represents only about $300 \mathrm{ml}$, which seems to be insignificant in terms of a man's variability in lung function, the difference becomes important if applied systematically to many miners for selections - such as job placement and compensation. Future developments in reference values should account for the curvature in the observed data with age (figs 2 and 3 ) and the changing socioeconomic status of the black population. 
These statistical considerations assume that the distribution of lung function measurements is normal. The skewness statistics in table 2 indicate that the distribution for FVC has a tail to the right, the distribution for $\mathrm{FEV}_{1}$ is normal, and the distribution for $\mathrm{FEV}_{1} \%$ has a tail to the left. This pattern is similar for black and white miners. Because of the skewness and variability in the distribution of the percentage predicted, the 5 th percentile and $80 \%$ predicted were suggested as preferable criteria for the LL, ${ }^{9}$ and are often used in clinical practice.

The use of $80 \%$ predicted as a criterion for abnormal is not recommended, for adults by the ATS. ${ }^{4}$ Although some studies have shown that $80 \%$ of predicted is close to the fifth percentile, ${ }^{9}$ other shortcomings inherent in the use of a fixed value of percentage predicted are that shorter, older subjects are more readily classified as abnormal, whereas taller, younger adult subjects are more likely to be erroneously classified as normal. ${ }^{4}$ In South Africa, it has been suggested that the grading of lung function impairment for compensation purposes should be based on percentage of predicted derived from the ECCS reference values. ${ }^{3}$ The percentage predicted categories of impairment for $\mathrm{FEV}_{1}$ and $\mathrm{FVC}$ were as follows: normal $\geqslant 80 \%, 79 \%-65 \%$ for mildly impaired, $64 \%-51 \%$ for moderately impaired, and $<51 \%$ for severely impaired. Here, we examined the percentage predicted values corresponding with the 5 th percentile and the lower $95 \%$ CIs, for different reference equations, according to age categories.

For FVC and $\mathrm{FEV}_{1}$, the lower $95 \%$ CIs (or the LLs) for the percentage predicted corresponded with $80 \%$ for values derived from the prediction equation and the equation of Louw et al, but was lower for the ECCS equation (table 3). The corresponding percentage predicted based on the prediction equation started to decrease below $80 \%$ at 50 years of age for FVC and at 40 years of age for $\mathrm{FEV}_{1}$. For $\mathrm{FEV}_{1} \%$, the corresponding percentage predicted started at around $89 \%$ for the youngest age category, and decreased to around $83 \%$ for the oldest age category. There was no important difference between the LL calculated as the 5 th percentile or the $95 \%$ CI. The percentage predicted values corresponding to the LL depend on how well the reference equation fits the actual data, but even for the best fitting linear curve, the values were age related. Because subjects older than 50 years of age have a steeper decline in lung function than the predicted values based on a linear regression curve, the $80 \%$ criterion might not be appropriate for the older subjects.

Figure 5 shows strong relations between height and age, which is likely to be due to a cohort effect. Correlation between predictor variables (age and height) violates the linear regression assumption of independently distributed explanatory variables and could lead to biased estimates for age and height, in particular an overestimated effect of age. In such a case, the variable for age may not be suitable for predicting longitudinal loss of lung function with years of age.
In summary, of the reviewed reference equations, ${ }^{5}$ the ECCS and Knudson equations best fitted the data for white miners. Although the two reference curves were similar with respect to the percentage of miners below the LL, the LLs derived from the ECCS equations were slightly better in terms of rejecting $5 \%$ of the subjects. For black miners, the reference equation of Louw et al estimated on healthy South African men fitted best, whereas the ECCS reference equations overestimated the percentage of subjects that were below the LL by $10 \%$ for FVC and $8 \%$ for $\mathrm{FEV}_{1}$. The ECCS reference values scaled by a factor of 0.93 for FVC and 0.95 for $\mathrm{FEV}_{1}$ provided a reasonably good fit to the data from black miners, however, the slope for FVC was too steep. The ECCS equations, with a conversion factor 0.88 for the black miners, are available on most spirometers sold in South Africa. However, the results of the present study show that the correction factor of 0.88 is too low and also that the ECCS curve for FVC is too steep to fit well.

Because of the strong correlation between height and age, the estimated regression variables for age may not be suitable for estimating the longitudinal loss due to years of age. The steep trend between height and age indicate that there is a strong cohort effect, and this supports the ATS recommendations that estimation of reference values should be repeated every decade or so.

We thank the mines for letting us use the lung function screening data and Ms Tanusha Singh for her computing support. The study received partial support from the Safety in Mining Research Advisory Committee (SIMRAC).

1 Occupational Health and Safety Act, Act 85 of 1993, with Regulations. Johannesburg: Butterworth, 1996.

2 Quanjer $\mathrm{PhH}$, Tammeling GJ, Cotes JE, et al. Lung volumes Quanjer PhH, Tammeling GJ, Cotes JE, et al. Lung volumes
and forced ventilatory flows. Eur Respir f 1993;6(suppl 16): and force

3 White N, Ehrlich R, Rees D. A guide to spirometry as applied to occupational health. S Afr Med F 1996;86:80713.

4 American Thoracic Society. Lung function testing: selection of reference values and interpretative strategies. Am Rev Respir Dis 1991;144:1202-18.

5 Louw SJ, Goldin JG, Joubert G. Spirometry of healthy adult

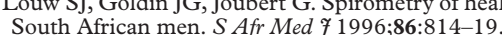

6 Hnizdo E, Churchyard G, Dowdeswell R. Assessment of reliability of a pulmonary function screening programme in the South African gold mines. Am $\mathcal{F}$ Respir Crit Care Med 1999;160:2006-11.

7 American Thoracic Society. Standardization of spirometry. Am f Respir Crit Care Med 1995;152:1107-36.

8 Vollmer WM. Reconciling cross-sectional with longitudinal observations on annual decline. Occup Med 1993;8:33951 .

9 Knudson RJ, Lebowitz MD, Holberg CJ, et al. Changes in the normal maximal expiratory flow-volume curve with growth and aging. Am Rev Respir Dis 1983;127:725-34

10 Snedecor GW, Cochran WG. Statistical methods, 6th ed. Iowa, USA: Iowa State University Press, 1967.

11 Hnizdo E. Combined effect of silica dust and tobacco smoking on mortality from chronic obstructive lung disease in gold miners. Br f Ind Med 1990;47:656-64.

12 White NW, Hanley JH, Lalloo UG, et al. Review and analysis of variation between spirometric values reported in 29 sis of variation between spirometric values reported in 29
studies of healthy African adults. Am f Respir Crit Care Med 1994;150:348-55

13 Mokoetle KE, de Beer M, Becklake MR. A respiratory survey in a black Johannesburg workforce. Thorax 1994;49: 340-6.

14 Hessel PA, Sluis-Cremer GK. Prediction equations for lung function in black industrial workers at Palabora Mining Company. S Afr Med f 1989;76:548-9.

15 Myers JE. Differential ethnic standards for lung functions, or one standard for all. S Afr Med F 1984;65:768-72. 